Article

\title{
\#Globalcitizen: An Explorative Twitter Analysis of Global Identity and Sustainability Communication
}

\author{
Marie Merle ${ }^{1}$, Gerhard Reese ${ }^{2, *(1)}$ and Stefan Drews ${ }^{3}$ \\ 1 Department of Psychology, University of Koblenz-Landau, 76829 Landau, Germany; \\ froileinmerle@gmail.com \\ 2 Department of Psychology, Environmental Psychology Research Unit, University of Koblenz-Landau, \\ 76829 Landau, Germany \\ 3 Institute of Environmental Science and Technology, Universitat Autònoma de Barcelona, \\ 08193 Barcelona, Spain; stefan.drews11@gmail.com \\ * Correspondence: reese@uni-landau.de; Tel.: +49-6341-28031460
}

Received: 28 May 2019; Accepted: 14 June 2019; Published: 25 June 2019

\begin{abstract}
Background: global citizenship is often associated with pro-social and pro-environmental attitudes, beliefs and behaviors. Much of this research relies on questionnaire studies, whereas studies drawing on naturally occurring daily communications are under-used. In this paper, we analyse the content that users publish on Twitter related to the issue of global identity and citizenship. (2) Methods: we assessed word frequencies and associated hashtags of 35,237 tweets marked with the hashtag \#globalcitizen. A sentiment analysis was conducted to investigate the moods and emotions of the tweets. (3) Results: in line with expectations derived from social identity theory, we found that associated words and hashtags were more often linked to themes of common good/disadvantaged groups than they were to the topic of nature and environment. Providing evidence for an empowerment function of global citizenship, the sentiment analysis suggests that global citizenship is related to rather positive emotions. (4) Conclusion: these findings reveal how identity constructions in social media predict associated contents and possibly pathways to social change.
\end{abstract}

Keywords: global citizenship; social identity; global identity; globalization; sentiment analysis; social networks; twitter

\section{Introduction}

The age of globalization is characterized by a rapid and growing interdependence of the global economy, political institutions and unprecedented opportunities for socio-cultural interactions $[1,2]$. The rise of the internet has accelerated the globalization process even further, with online social network sites having become channels to express political opinions and communicate with people across the globe. With these forms of increasing interconnectedness, several scholars argued that new forms of social identification may emerge. These can transcend national and cultural boundaries [3], potentially up to the point of identifying with a common human identity $[4,5]$ or as a global citizen [6]. These forms of identification, in turn, can motivate pro-social [7] as well as pro-environmental [8] behaviour and thus, contribute to societal change.

In this research, we seek to uncover whether the concept of a common human identity or global citizenship finds expression in the public, and whether it would be related to corresponding pro-social and pro-environmental contents. The microblogging platform Twitter in particular has become a channel to express global and political opinions [9]. At the same time, such social network sites serve as platforms for the grouping of social movements [10], with recent evidence suggesting that (even artificial) chats with people from other cultures indeed increase global identity [11]. 
We thus seek to expand research on global citizenship and globally responsible actions by looking at public expressions of global citizenship and the goals and concepts communicated alongside with it. To do so, we conducted a Twitter analysis exploring tweets tagged with \#globalcitizen. Our analysis will thus build a bridge between social identity theorizing and global movement indicators. It allows us to explore whether the conclusions derived from previous lab and survey research also find expression in online communication. Given that most research on global identity is based on laboratory studies and/or self-report measures, we deem it important to show that the conceptual ideas of global citizenship find expression in methods less susceptible to social desirability concerns and other demand characteristics.

\section{Theoretical Background and Hypotheses Development}

\subsection{Social Identity and Global Citizenship}

Processes of identity are vital to understanding group formation, identity expression and communication in social media (e.g., refs. [12,13]). When we speak of global citizenship or global identity, we refer to social identification on the highest level of abstraction. According to social identity theory [14], human identity ranges on a continuum from a purely personal to a social group-based identity. Personal identity contains knowledge about oneself, whereas social identity describes the perceived membership of a social group. Comparative processes take place at both ends of the continuum, from "I" vs. "you" [15] to "we" vs. "the others" [16]. The comparison between social groups often results in favour of the own group ("we") and is accompanied by a devaluation of the foreign group ("the others") $[14,17]$. This means that each commitment of the individual serves the good of the entire group. In addition, members of a group strive to stand up for group-specific interests and to act in the group's interest [18]. Social identity thereby becomes a vehicle of societal change ([2] as groups rather than individuals, have the potential for impact (e.g., collective action; see [19].

Strongly related to social identity theory, self-categorization theory [18] provides an explanation for when and how people become group members and on which levels they categorize themselves. The focus is no longer on the personal identity, but on the perception of oneself in a social category [20] and the feeling of subjective similarity to this very category [21]. Subsequently, the expression of group-specific characteristics dominates the expression of one's own self. This increases the subjective similarity with other group members and strengthens the homogeneity within the group [15]. Turner et al. [18] propose three different levels of inclusivity of self-categorization: at the lowest level is the individual with his personal identity, at the middle level is group identity and at the highest level the is identification with all people.

Despite this early division into the three levels of self-categorization, the idea that we can identify with the group "all humans", i.e., as a global citizen, has only recently gained increasing scientific attention. Arnett [22] assumes that, shaped by globalization and the increasing interconnection of the world, people become more prone to form bicultural identities. In addition to their local identity, they would develop a global identity that provides them a feeling of global and cultural solidarity. Buchan, Brewer, Grimalda, Wilson, Fatas and Foddy [4] found evidence that globalization tends to work in the direction of global citizenship. In a large international study (comprising samples from Argentina, Iran, Italy, Russia, South Africa and United States) they found that the extent and endorsement of globalization at both collective (national) and individual levels were related to global cooperation. Specifically, the more globalized a nation and its individuals, the broader were people's group boundaries and the more they cooperated on a global scale. Accordingly, global identity can be understood as the identification of individuals with all humanity [7] or with the earth and its people [8].

Thus, as global citizens, they will not only be concerned with their local issues, but with their responsibility within different communities and the world community [23]. Consistent with social identity claims, each commitment of the individual serves the good of the entire group. Consequently, 
global identity captures psychological and emotional investments of a single global citizen which benefits the entire world community [24-26].

In fact, numerous studies in psychology suggest that higher identification on a global levels predicts stronger commitments for the "global ingroup". Further studies have shown that people with global identity are more likely to support disadvantaged groups $[7,27,28]$. They tend to endorse transnational cooperation [4] and also have a higher environmental awareness [5,6,8,19]. Global identity correlates negatively with ethnocentrism, social dominance orientation and right-wing authoritarianism [29]. With the potential of a global identity to empower people to contribute to social change, it is plausible to assume that positive emotions are an important mediator between global identity and the behavioral outcomes. However, to our knowledge, there is no research to date showing this link. Related research from empowerment processes suggest that positive emotions (such as joy or anticipation) may indeed be linked to empowerment [30], and thus, positive social change [31].

\subsection{Interaction and Identity in Online-Based Social Networks}

The internet offers people the opportunity to organize and unite digitally. Consequently, common identities can emerge from previously heterogeneous groups [32]. Social-psychological research has shown that social network sites support individuals in communication, in the expression of protest, in informing the public and in forming collective common identities [33,34]. Posts on Twitter (tweets; messages with a maximum of 240 characters) are largely shared publicly [35]. Using hashtags (\#), they are visibly tagged for everyone and can thus be assigned to a specific topic. By the means of an at-sign (@), other users are addressed directly. This form of publicity is also one of the reasons why Twitter is used by its users to spread political opinions and statements [36]. They can share information, comment on it and publicly reinforce and unite based on their worldview [37].

This is how opinion-based social identities can emerge where group members use digital channels to express their point of view to a foreign group [38]. One example is the Occupy-Wallstreet movement, where political discussions on Facebook have led to demonstrations in the real world [39]. As a result, online based activism can influence the activism outside of the internet [12,40].

A study by Smith and colleagues [41] investigated whether the perception of a normative conflict-a discrepancy between the way the world actually is and how individuals would rather like to see it-motivates people to communicate this state via Twitter in the hope of changing it. The results indicate that the publication of personal opinions is associated with a desire of social change. Thus, social media is becoming a more important source for the exploration of language use and intentional behavior [42]. Based on the high number of daily published messages, it seems possible to explore collective trends via tweets and make predictions for social, political and cultural phenomena [9].

\subsection{Hypotheses}

Social network sites create digital places where people can inform themselves about events in the world and easily exchange and unite with others in public. This combination of information and interaction facilitates the commitment to a global identity and with that the commitment to humanity and the planet. As an expression for this, several hashtags, such as \#globalidentity, \#globalcitizenship or \#globalcitizen are relevant. Since the hashtag \#globalcitizen seems to be the most popular term, this paper will explore the type of content tagged by this keyword. Based on our reasoning above, we test two hypotheses:

Hypothesis 1. Words and hashtags associated with \#globalcitizen are related to the subjects of nature and environment as well as disadvantaged groups.

Hypothesis 2. The emotional content of tweets with \#globalcitizen are rather positive than negative due to their empowerment function related to nature and environment, as well as disadvantaged groups. 


\section{Method}

Data set: the subject of this paper is a corpus of publicly available tweets with the hashtag \#globalcitizen. It contains 35,237 English-language tweets, published between December 30, 2017 (6:42 p.m.) and June 30, 2018 (11:58 p.m.) (due to technical problems, tweets could not be downloaded from January 29, 2018 (6:33 p.m.) to February 2, 2018 (4:10 p.m.) and from April 10, 2018 (10:31 a.m.) to April 22, 2018 (09:39 a.m.)). All tweets were captured with Twitter Archiver (https://gsuite. google.com/marketplace/app/tweet_archiver/976886281542) and automatically saved in Google Sheets (https://www.google.com/sheets/about/) at Google Drive (https://www.google.com/drive/). Both the tweet text and the following associated information were recorded: date, screen name, full name, tweet ID, app, follower, follows, retweets, favorites, verified, user since, location, bio, profile image.

Data preparation: R Studio (https://www.rstudio.com/) was used to prepare the data and analyze the tweets. As part of the preparation process, URLs and emojis were deleted. Retweets were also removed. Although retweets can express the personal opinion of a user, they can also be commented negatively on with the same words, and thus distort the original message [37]. In the next step, the tweets were divided into tokens [43]. To do this, the punctuation was removed so that words are separated only by a space. Stop words, such as: 'a' , 'an', 'the', or 'of', and pure numbers are deleted. The result is a list of 225,249 words, which can also contain a hashtag (\#) or a reference to a user profile(@).

Sentiment Analysis: for the sentiment analysis, all tweets were analyzed in their original form. The classification of the mood ('sentiment') takes place in two steps: first, the mood per tweet was determined with the 'sentimentr' package. A sentiment score was calculated for each tweet by setting positive words to +1 and negative words to -1 . The average sentiment per tweet is calculated according to the total number of words and the sum of positive and negative words. The second step is to check the type of words appearing in the tweets. The basis for this is the free NRC Word-Emotion Association Lexicon of Mohammad and Turney [44]. It contains the most commonly used subjectives, verbs, adjectives and adverbs of the English language-a total of 14,182 words. Each of these words was assigned to at least one of eight emotions ('joy', 'sadness', 'trust', 'disgust', 'anger', 'fear', 'surprise', 'anticipation') and a positive or negative sentiment.

\section{Results}

We first tested Hypothesis 1, analysing the hashtags and words associated with \#globalcitizen. Table 1 shows the 15 most common words mentioned with \#globalcitizen. Tweets were categorized into two groups: "Nature and Environment" and "Disadvantaged Groups". Besides that, selected tweets were added as examples to illustrate the content classification. Across all tweets, 'world' is the most frequently used word $(n=4606)$. Together with the word 'global', they are mentioned in different contexts and can therefore be assigned to the two categories "Nature and Environment" and "Disadvantaged Groups". "Nature and Environment" is the most frequently assigned category. The reason for this is the event of the water drought in Cape Town, and the wide spread of a specific tweet in which the words 'town', 'cape', 'living', 'scarce' and 'regions' appear. 
Table 1. Associated words with \#globalcitizen by frequency.

\begin{tabular}{|c|c|c|c|}
\hline Word & Count & Example & Category \\
\hline world & 4606 & $\begin{array}{l}\text { These Are the } 10 \text { Most and Least Peaceful Countries } \\
\text { in the World https://t.co/kPe5kPGb0u \#globalcitizen }\end{array}$ & $\begin{array}{l}\text { Nature and Environment, } \\
\text { Disadvantaged Groups }\end{array}$ \\
\hline people & 3544 & $\begin{array}{l}\text { Refugee? Migrant? Human Being. Show Your } \\
\text { Support for All People - No Matter Where They Were } \\
\text { Born https://t.co/AnzE8Bkf55 \#globalcitizen }\end{array}$ & Disadvantaged Groups \\
\hline water & 3473 & $\begin{array}{l}\text { Fill your own reusable cup or bottle. Don't buy } \\
\text { \#bottledwater. http://glblctzn.me/298VloW }\end{array}$ & Nature and Environment \\
\hline stand & 3110 & $\begin{array}{l}\text { PLEASE \#SIGN! Stand Up for the \#Arctic! } \\
\text { https://t.co/RAPQ4GbcIS \#globalcitizen }\end{array}$ & Nature and Environment \\
\hline town & 2881 & $\begin{array}{l}\text { As a \#GlobalCitizen I stand with Cape Town \& the } \\
\text { 2bn people living in water-scarce regions. Let's work } \\
\text { with world leaders, businesses, institutions, \& } \\
\text { individuals to create a water-secure world }\end{array}$ & Nature and Environment \\
\hline cape & 2864 & $\begin{array}{l}\text { As a \#GlobalCitizen I stand with Cape Town \& the } \\
\text { 2bn people living in water-scarce regions. Let's work } \\
\text { with world leaders, businesses, institutions, \& } \\
\text { individuals to create a water-secure world }\end{array}$ & Nature and Environment \\
\hline living & 2845 & $\begin{array}{l}\text { As a \#GlobalCitizen I stand with Cape Town \& the } \\
\text { 2bn people living in water-scarce regions. Let's work } \\
\text { with world leaders, businesses, institutions, \& } \\
\text { individuals to create a water-secure world }\end{array}$ & Nature and Environment \\
\hline scarce & 2805 & $\begin{array}{l}\text { As a \#GlobalCitizen I stand with Cape Town \& the } \\
\text { 2bn people living in water-scarce regions. Let's work } \\
\text { with world leaders, businesses, institutions, \& } \\
\text { individuals to create a water-secure world }\end{array}$ & Nature and Environment \\
\hline regions & 2803 & $\begin{array}{l}\text { As a \#GlobalCitizen I stand with Cape Town \& the } \\
\text { 2bn people living in water-scarce regions. Let's work } \\
\text { with world leaders, businesses, institutions, \& } \\
\text { individuals to create a water-secure world }\end{array}$ & Nature and Environment \\
\hline women & 2092 & $\begin{array}{l}\text { Millions of Girls and Women Are Still the Victims of } \\
\text { Genital Mutilation, Sign Our Petition... } \\
\text { https://t.co/aE5twKdJrK \#globalcitizen }\end{array}$ & Disadvantaged Groups \\
\hline girls & 1982 & $\begin{array}{l}\text { Menstruation Huts Are Illegal in Nepal, But Girls on } \\
\text { Periods Are Still in Danger There } \\
\text { https://t.co/5YRk5gG6QX \#globalcitizen }\end{array}$ & Disadvantaged Groups \\
\hline ensure & 1627 & $\begin{array}{l}\text { Call on World Leaders to Ensure Everyone Has } \\
\text { Access to Toilets https://t.co/ETrl2O2B4W } \\
\text { \#globalcitizen }\end{array}$ & Disadvantaged Groups \\
\hline child & 1507 & $\begin{array}{l}\text { Stand with Sonita: Tell World Leaders to End Child } \\
\text { Marriage https://t.co/pRtv0Koa4Y \#globalcitizen }\end{array}$ & Disadvantaged Groups \\
\hline global & 1463 & $\begin{array}{l}\text { \#GlobalCitizen "The climate is a common good, } \\
\text { belonging to all and meant for all. At the global level, } \\
\text { it is a complex system linked to many of the essential } \\
\text { conditions for human life" @PopeFrancis A visit: } \\
\text { https://cafod.org.uk/Pray/Laudato-Si-encyclical }\end{array}$ & $\begin{array}{l}\text { Nature and Environment, } \\
\text { Disadvantaged Groups }\end{array}$ \\
\hline @usaid & 1411 & $\begin{array}{l}\text { @USAID will the US continue to be a leader for } \\
\text { global education and a \#globalcitizen with a } \$ 337.5 \mathrm{M} \\
\text { pledge to @GPForEducation? Look forward to seeing } \\
\text { @USAIDMarkGreen in Dakar on 2/2/18 to represent } \\
\text { US and \#FundEducation. }\end{array}$ & Disadvantaged Groups \\
\hline
\end{tabular}

A total of 2926 associated hashtags with \#globalcitizen were identified. Table 2 shows hashtags that have been mentioned at least 100 times (an arbitrarily set cut-off for the sake of clarity). Across all tweets, \#levelthelaw was mentioned most often $(n=743)$. This hashtag stands for the fight against unjust laws and discrimination against girls and women. \#hlpwater and \#safesluges are hashtags which are mostly mentioned in a certain tweet. The tweets including these two hashtags are addressed 
to the High-Level Panel on Water and Peace, a body of the United Nations, with the intention to eliminate the danger of toxic faecal sludge. The hashtag \#refugeeswelcome is used as an expression of a positive welcome culture for refugees. \#investined and \#fundeducation stand for investment in education worldwide. Finally, the hashtag \#globalgoals is a hybrid of various demands, e.g.: climate protection, fight against poverty and gender equality. Hashtags assigned to the category of "Disadvantaged Groups" are most frequently used. As damage to nature and the environment can often have consequences for people living in these areas, the category "Nature and Environment" was chosen together with "Disadvantaged Groups" for some hashtags (\#hlpwater, \#safesludges, \#globalgoals).

Table 2. Associated hashtags with \#globalcitizen by frequency.

\begin{tabular}{|c|c|c|c|}
\hline Hashtag & Count & Example & Category \\
\hline \#levelthelaw & 743 & $\begin{array}{l}\text { Sign the petition to help the millions of women \& } \\
\text { children being raped and sold: } \\
\text { https://t.co/itqT2llrf0 \#globalcitizen \#levelthelaw }\end{array}$ & Disadvantaged Groups \\
\hline \#hlpwater & 677 & $\begin{array}{l}\text { @EPN @JJGomezCamacho @aguribfakim pls } \\
\text { ensure \#HLPWater prioritizes fecal sludge mgmt } \\
\text { so all can survive \& thrive \#GlobalCitizen } \\
\text { \#SafeSludge }\end{array}$ & $\begin{array}{l}\text { Nature and Environment, } \\
\text { Disadvantaged Groups }\end{array}$ \\
\hline \#safesludge & 674 & $\begin{array}{l}\text { @EPN @JJGomezCamacho @aguribfakim pls } \\
\text { ensure \#HLPWater prioritizes fecal sludge mgmt } \\
\text { so all can survive \& thrive \#GlobalCitizen } \\
\text { \#SafeSludge }\end{array}$ & $\begin{array}{l}\text { Nature and Environment, } \\
\text { Disadvantaged Groups }\end{array}$ \\
\hline \#refugeeswelcome & 671 & $\begin{array}{l}\text { @realDonaldTrump Syrian refugees deserve safe } \\
\text { shelter. The US can do more for the most } \\
\text { vulnerable. Be a \#GlobalCitizen } \\
\text { \#RefugeesWelcome }\end{array}$ & Disadvantaged Groups \\
\hline \#investined & 204 & $\begin{array}{l}\text { @RepYvetteClarke Investing in education is } \\
\text { investing in our future. Support } \$ 925 \mathrm{~m} \text { in basic ed } \\
\text { funding in FY18 \#GlobalCitizen \#InvestInEd }\end{array}$ & Disadvantaged Groups \\
\hline \#globalgoals & 131 & $\begin{array}{l}\text { Sustainable Development Goal 2: No Hunger. } \\
\text { Everyone's participation needed. \#SDGS \#sdg2 } \\
\text { \#globalgoals \#2030now \#glblctzn \#globalcitizen } \\
\text { \#sustainabledevelopment \#worldwewant } \\
\text { \#UNYouth \#UNWomen \#Socialgood } \\
\text { \#Unitednations \#UNDP \#YouthCSWForum } \\
\text { @YouthForumCSW @UN_CSW @UN4Youth }\end{array}$ & $\begin{array}{l}\text { Nature and Environment, } \\
\text { Disadvantaged Groups }\end{array}$ \\
\hline \#fundeducation & 100 & $\begin{array}{l}\text { This is one of @GlblCtzn 's biggest advocacy } \\
\text { priorities for } 2018 \text { \#FundEducation \#GlobalCitizen } \\
\text { https://t.co/EPwFwBiAfL }\end{array}$ & Disadvantaged Groups \\
\hline
\end{tabular}

The sentiment analysis evaluates emotions and moods related to \#globalcitizen. The average number of words per tweet is 16.88 , with an average sentiment score of 0.08 (Table 3). The tweets' sentiment is therefore rather positive (i.e., different from zero, $\mathrm{t}[35236]=67.09, p<0.001$ ). A similar result is shown by the type of words that appear in the tweets. The number of positive words $(60.2 \%)$ is higher than the number of negative words (39.8\%) (Table 4). Furthermore, words expressing positive emotions ('joy', 'trust', 'surprise', 'anticipation') occur on average more frequently in the tweets (56.4\%) than words expressing negative emotions ('sadness', 'disgust', 'anger', 'fear'; 44.6\%) (Table 5).

Table 3. Sentiment score for all tweets.

\begin{tabular}{ccc}
\hline Variable & Mean & SD \\
\hline Word frequency per tweet & 16.88 & 3.80 \\
\hline Sentiment score & 0.08 & 0.23 \\
\hline
\end{tabular}


Table 4. Frequency of positive and negative words.

\begin{tabular}{ccc}
\hline Sentiment & Total & Share \\
\hline Positive & 23.789 & $60.2 \%$ \\
\hline Negative & 15.712 & $39.8 \%$ \\
\hline Total & 39.501 & $100 \%$ \\
\hline
\end{tabular}

Table 5. Frequency of words on hashtag-based emotions.

\begin{tabular}{ccc}
\hline Emotion & Total & Share \\
\hline Joy & 10.745 & $15.8 \%$ \\
Sadness & 8.432 & $12.4 \%$ \\
Trust & 14.512 & $21.4 \%$ \\
Disgust & 5.940 & $8.7 \%$ \\
Anger & 6.088 & $9.0 \%$ \\
Fear & 9.697 & $14.3 \%$ \\
Surprise & 2.028 & $3.0 \%$ \\
Anticipation & 10.490 & $15.4 \%$ \\
\hline Total & 67.932 & $100 \%$ \\
\hline
\end{tabular}

\section{Discussion}

This paper makes an initial contribution to the study of global identity and its related outcomes on the Internet. Specifically, an analysis of 35,237 tweets with the hashtag \#globalcitizen suggests that Twitter is used as a platform to express global identity and related demands. Two hypotheses have been put forward. We assumed in Hypothesis 1 that words and hashtags associated with \#globalcitizen were related to the subjects of "Disadvantaged Groups" as well as "Nature and Environment". For the analysis, frequencies of words and hashtags in tweets tagged with \#globalcitizen were identified and sorted into four categories. A global identification with humans and planet is recognizable. In addition,' action words' are used to call for action, so that it is not just a proclamation of grievances. Among the most common words, only one 'recipient' (@usaid) could be found. The identification with a superordinate group marked by the hashtag \#globalcitizen and the call to (prosocial) behavior is similar to the theory of the common ingroup identity model [45]. The commitment of the individual can therefore be understood as a commitment to the whole group respectively to people worldwide [17]. However, the base of this work are social-psychological theories that primarily explain human behavior outside the internet. Based on the results and the increasing global networking through the internet, there is a need to extend the theoretical assumptions on global identity with digital behaviors (see also [41], for work on global solidarity). This allows us to ensure consistency in the interpretation of the results. Furthermore, associated hashtags were analysed, which confirmed theoretical considerations. Global citizens are generally committed to "Disadvantaged Groups" as well as "Environment and Nature", which finds expression in that hashtags were used more frequently in the context of "Disadvantaged Groups" than "Environment and Nature". Expressions of ethnocentrism, social dominance orientation and right-wing authoritarianism could not be recognized. However, it should be noted that only hashtags which occurred at least 100 times were considered. Hence, individual cases were not taken into account in this analysis. Finally, the spread of the hashtag \#globalcitizen and its associated hashtags may also help to mobilize users less committed to the goals of world citizens for their cause [46]. Hansen et al. [47] have shown that tweets with a positive sentiment are more likely to spread than those with a negative sentiment-with the exception of current news. Thus, in order to reach a large number of users, it is therefore advisable to consciously select hashtags and adapt them to the needs of potential target group(s).

Hypothesis 2 postulated that tweets with \#globalcitizen have an affectively more positive than negative content due to their appeal function in connection with the commitment to nature and environment as well as disadvantaged groups. A sentiment analysis was carried out, suggesting 
that the sentiment per tweet was rather positive. Furthermore, the analysis revealed that words expressing positive emotions and positive words in general were more frequently used than negative words and emotions. Yet, it is not surprising that the overall sentiment for all tweets did not turn our as highly positive. Tweets often deal with grievances in the world and point out what should be improved from the users' point of view. Therefore, it is possible that positive and negative words have partially balanced each other out when estimating the sentiment score. In other words, users have recognized global crises (negative) and formulate proposals for solutions (positive) to political decision-makers in a form of collective activism [35]. As exemplified above, research on empowerment suggests that positive emotions may facilitate empowerment and ultimately, positive social change. A recent model originating from social identity theory, the social identity model of pro-environmental action (SIMPEA, [48]), predicts that the feeling of collective efficacy (i.e., perceiving that one's group can really change something) may indeed foster pro-environmental action (see also [49]).

Finally, some limitations of our study deserve attention. First, as we only used English tweets and the \#globalcitizen, this study can neither provide representativeness nor fulfil a claim for completeness. This could be addressed in future research, looking at a diverse set of languages and hashtags (although, we are not aware of similarly abundant terms for global identity in other languages). Second, it is a cross-sectional analysis that analyses tweets on \#globalcitizen within a period of six months so that single events may have had a substantial influence on the results (although we are not aware of any except for the one described in the results section). For future research projects, however, it is recommended to evaluate the data over a longer period of time in order to avoid content distortions. And third, we focused on the frequencies of words rather than their specific content. Future studies should therefore examine to what extent a decomposition of tweets into fragments with two or more words (n-grams) will lead to different results [50]. This approach may allow a deeper understanding of the demands related to global identity.

A similar procedure is also recommended for the sentiment analysis. Sentiments and emotions were captured on a word basis. The sentiment of a tweet may not be correctly determined because of irony, which is not considered in the analysis. In addition, compound and negatively connotated terms ('child marriage') have also be evaluated positively as individual words ('child', 'marriage'). It is therefore recommended to proceed the sentiment analysis with other lexicons (z. B. Bing [51] or LIWC [52] and to compare their results afterwards.

Basically, it remains open how strongly users identify globally despite their tweets to \#globalcitizen and to what extent they are actually active inside or outside of the Internet. Based on the present work, however, it is plausible to assume that the current findings are valid, as they resonate strongly with experimental and survey research on global identity. Combining these methods with a parallel analysis of Twitter data will enable a comprehensive, scientific understanding of global identity and its ramifications, both in online and offline contexts.

Author Contributions: Conceptualization, M.M., G.R., S.D.; methodology, M.M., G.R., S.D. software, M.M.; data curation and interpretation, M.M. \& G.R.; writing-original draft preparation, M.M. \& G.R.; writing-review and editing, M.M., G.R., S.D.; supervision, G.R.

Funding: This research received no external funding.

Conflicts of Interest: The authors declare no conflict of interest.

\section{References}

1. Chryssochoou, X. Cultural Diversity: Its Social Psychology; Blackwell: Oxford, UK, 2005.

2. Rosenmann, A.; Reese, G.; Cameron, J.E. Social Identities in a Globalized World: Challenges and Opportunities for Collective Action. Perspect. Psychol. Sci. 2016, 11, 202-221. [CrossRef] [PubMed]

3. Smith, L.G.; Gavin, J.; Sharp, E. Social identity formation during the emergence of the occupy movement. Eur. J. Soc. Psychol. 2015, 45, 818-832. [CrossRef]

4. Buchan, N.R.; Brewer, M.B.; Grimalda, G.; Wilson, R.K.; Fatas, E.; Foddy, M. Global social identity and global cooperation. Psychol. Sci. 2011, 22, 821-828. [CrossRef] [PubMed] 
5. Reese, G. Common human identity and the path to global climate justice. Clim. Chang. 2016, 134, 521-531. [CrossRef]

6. Reysen, S.; Katzarska-Miller, I. A model of global citizenship: Antecedents and outcomes. Int. J. Psychol. 2013, 48, 858-870. [CrossRef]

7. McFarland, S.; Webb, M.; Brown, D. All humanity is my ingroup: A measure and studies of identification with all humanity. J. Personal. Soc. Psychol. 2012, 103, 830-853. [CrossRef]

8. Renger, D.; Reese, G. From Equality-Based Respect to Environmental Activism: Antecedents and Consequences of Global Identity. Political Psychol. 2017, 38, 867-879. [CrossRef]

9. Bollen, J.; Mao, H.; Pepe, A. Modeling public mood and emotion: Twitter sentiment and socio-economic phenomena. ICWSM 2011, 11, 450-453.

10. McAdam, D.; Tarrow, S.; Tilly, C. Dynamics of Contention; Cambridge University Press: Cambridge, UK, 2001.

11. Römpke, A.K.; Fritsche, I.; Reese, G. Get Together, Feel Together, Act Together: International Personal Contact Increases Identification with Humanity and Global Collective Action. J. Theor. Soc. Psychol. 2019, 3, 35-48. [CrossRef]

12. Harlow, S. Social Media and Social Movements: Facebook and an Online Guatemalan Justice Movement that Moved Offline. New Med. Soc. 2012, 14, 225-243. [CrossRef]

13. Valkenburg, P.M.; Schouten, A.P.; Peter, J. Adolescents' identity experiments on the Internet. New Med. Soc. 2005, 7, 383-402. [CrossRef]

14. Tajfel, H.; Turner, J.C. An integrative theory of intergroup conflict. Soc. Psychol. Intergr. Relat. 1979, 33, 33-47.

15. Haslam, S.A. Psychology in Organizations: The Social Identity Approach, 2nd ed.; Sage: Thousand Oaks, CA, USA, 2004.

16. Tajfel, H.; Billig, M.G.; Bundy, R.P.; Flament, C. Social Categorization and Intergroup Behaviour. Eur. J. Soc. Psychol. 1971, 1, 149-178. [CrossRef]

17. Tajfel, H. Experiments in a Vacuum. In The Context of Social Psychology: A Critical Assessment; Israel, J., Tajfel, H., Eds.; Academic Press: London, UK, 1972.

18. Turner, J.C.; Hogg, M.A.; Oakes, P.J.; Reicher, S.D.; Wetherell, M.S. Rediscovering the Social Group: A Self-Categorization Theory; Blackwell: Cambridge, UK, 1987.

19. Van Zomeren, M.; Postmes, T.; Spears, R. Toward an integrative social identity model of collective action: A quantitative research synthesis of three socio-psychological perspectives. Psychol. Bull. 2008, 134, 504-535. [CrossRef]

20. Mackie, D.M.; Hamilton, D.L.; Susskind, J.; Rosselli, F. Social Psychological Foundations of Stereotype Formation. In Stereotypes and Stereotyping; Macrae, C.N., Stangor, C., Hewstone, M., Eds.; Guilford: New York, NY, USA, 1996; pp. 41-78.

21. Hogg, M.A.; Reid, S.A. Social identity, self-categorization, and the communication of group norms. Commun. Theory 2006, 16, 7-30. [CrossRef]

22. Arnett, J.J. The psychology of globalization. Am. Psychol. 2002, 57, 774-783. [CrossRef]

23. Amponsah, C.T.; Ahmed, G.; Othman, S.M.; Harran, M. In Search of Global Identity: The Challenges of Culture. J. Hum. Resour. Adult Learn. 2016, 12, 16-28.

24. Reicher, S. The context of social identity: Domination, resistance, and change. Polit. Psychol. 2004, 25, 921-945. [CrossRef]

25. Tajfel, H.; Turner, J.C. The Social Identity Theory of Intergroup Behavior. In The Psychology of Intergroup Relations; Worchel, S., Austin, W.G., Eds.; Nelson-Hall Publishers: Chicago, IL, USA, 1986; pp. 7-24.

26. Der-Karabetian, A.; Ruiz, Y. Affective bicultural and global-human identity scales for Mexican-American adolescents. Psychol. Rep. 1997, 80, 1027-1039. [CrossRef] [PubMed]

27. Reese, G.; Kohlmann, F. Feeling global, acting ethically: Global identification and fair-trade consumption. J. Soc. Psychol. 2015, 155, 98-106. [CrossRef] [PubMed]

28. McFarland, S.; Brown, D.; Webb, M. Identification with all humanity as a moral concept and psychological construct. Curr. Dir. Psychol. Sci. 2013, 22, 194-198. [CrossRef]

29. McFarland, S. Authoritarianism, social dominance, and other roots of generalized prejudice. Polit. Psychol. 2010, 31, 453-477. [CrossRef]

30. Drury, J.; Reicher, S. Collective psychological empowerment as a model of social change: Researching crowds and power. J. Soc. Issues 2009, 65, 707-725. [CrossRef] 
31. Drury, J.; Cocking, C.; Beale, J.; Hanson, C.; Rapley, F. The phenomenology of empowerment in collective action. Br. J. Soc. Psychol. 2005, 44, 309-328. [CrossRef]

32. Postmes, T.; Brunsting, S. Collective action in the age of the internet. Soc. Sci. Comput. Rev. 2002, 20, $290-301$. [CrossRef]

33. Allagui, I.; Kuebler, J. The Arab Spring and the role of ICTs-Editorial introduction. Int. J. Commun. 2011, 5, 1435-1442.

34. Della Porta, D.; Diani, M. Social Movements: An Introduction; Blackwell Publishers Inc.: Malden, MA, USA, 2006; Volume 2.

35. Stieglitz, S.; Dang-Xuan, L. Political Communication and Influence through Microblogging-An Empirical Analysis of Sentiment in Twitter Messages and Retweet Behavior. In Proceedings of the 2012 45th Hawaii International Conference on System Sciences (HICSS), Maui, HI, USA, 4-7 January 2012; pp. 3500-3509.

36. Tumasjan, A.; Sprenger, T.O.; Sandner, P.G.; Welpe, I.M. Predicting Elections with Twitter: What 140 Characters Reveal About Political Sentiment. ICWSM 2010, 10, 178-185.

37. Boyd, D.; Golder, S.; Lotan, G. Tweet, Tweet, Retweet: Conversational Aspects of Retweeting on Twitter. In Proceedings of the 2010 43rd Hawaii International Conference on System Sciences, Maui, HI, USA, 5-8 January 2010; pp. 1-10.

38. McGarty, C.; Thomas, E.F.; Lala, G.; Smith, L.G.; Bliuc, A.M. New Technologies, New Identities, and the Growth of Mass Opposition in the Arab Spring. Polit. Psychol. 2014, 35, 725-740. [CrossRef]

39. Castells, M. Networks of Outrage and Hope: Social Movements in the Internet Age; Polity Press: Cambridge, UK, 2012.

40. Mercea, D. Digital Prefigurative Participation: The Entwinement of Online Communication and Offline Participation in Protest Events. New Med. Soc. 2011, 14, 153-169. [CrossRef]

41. Smith, L.; McGarty, C.; Thomas, E. After Aylan Kurdi: How Tweeting about Death, Threat, and Harm Predict Increased Expressions of Solidarity with Refugees over Time. Psychol. Sci. 2018, 29, 1-12. [CrossRef]

42. Beißwenger, M.; Storrer, A. Corpora of Computer-Mediated Communication. In Corpus Linguistics. An International Handbook; Lüdeling, A., Kytö, M., Eds.; Mouton de Gruyter: Berlin, Germany; New York, NY, USA, 2008; pp. 292-308.

43. Welbers, K.; Van Atteveldt, W.; Benoit, K. Text analysis in R. Commun. Methods Meas. 2017, 11, $245-265$. [CrossRef]

44. Mohammad, S.M.; Turney, P.D. Crowdsourcing a word-emotion association lexicon. Comput. Intell. Int. J. 2013, 29, 436-465. [CrossRef]

45. Gaertner, S.L.; Dovidio, J.F.; Anastasio, P.A.; Bachman, B.A.; Rust, M.C. The Common Ingroup Identity Model: Recategorization and the Reduction of Intergroup Bias. In European Review of Social Psychology; Strobe, W., Hewstone, M., Eds.; Wiley: London, UK, 1993; Volume 4, pp. 1-26.

46. Bimber, B.; Flanagin, A.J.; Stohl, C. Reconceptualizing collective action in the contemporary media environment. Commun. Theory 2005, 15, 365-388. [CrossRef]

47. Hansen, L.K.; Arvidsson, A.; Nielsen, F.Å.; Colleoni, E.; Etter, M. Good friends, bad news-affect and virality in twitter. In Future Information Technology; Springer: Berlin, Germany, 2011; pp. 34-43.

48. Fritsche, I.; Barth, M.; Jugert, P.; Masson, T.; Reese, G. The social identity model of pro-environmental action (SIMPEA). Psychol. Rev. 2018, 125, 245-269. [CrossRef]

49. Reese, G.; Junge, E.A. Keep on rocking' in a (plastic-)free world: Collective efficacy and pro-environmental intentions as a function of task difficulty. Sustainability 2017, 9, 200. [CrossRef]

50. Pak, A.; Paroubek, P. Twitter as a corpus for sentiment analysis and opinion mining. In Proceedings of the Seventh Conference on International Language Resources and Evaluation (LREC'10), Valletta, Malta, 19-21 May 2010; Volume 10.

51. Liu, B. Sentiment analysis and opinion mining. Synth. Lect. Hum. Lang. Technol. 2012, 5, 1-167. [CrossRef]

52. Pennebaker, J.W.; Booth, R.J.; Francis, M.E. Linguistic Inquiry and Word Count: LIWC; Erlbaum Publishers: Austin, TX, USA, 2006.

(C) 2019 by the authors. Licensee MDPI, Basel, Switzerland. This article is an open access article distributed under the terms and conditions of the Creative Commons Attribution (CC BY) license (http://creativecommons.org/licenses/by/4.0/). 